\title{
Lumbar Spinal Chondroma Presenting with Acute Sciatica
}

\author{
Dong Hwan Kim, Kyoung Hyup Nam, Byung Kwan Choi, Inho Han
}

Department of Neurosurgery and Medical Research Institute, Pusan National University School of Medicine, Busan, Korea

A 47-year-old woman visited with lumbago and severe left leg pain that had been presented for 1 week. The patient complained of severe radiating pain on left L3 sensory dermatome area and reported aggravation of leg pain at 20 degrees of hip flexion by straight leg raising test (SLRT). However, there was no motor weakness on neurological examination. Magnetic resonance imaging (MRI) demonstrated contrast enhancing spinal extradural mass at L2-3 level that was iso-signal intensity (SI) on T1-weighted images (WI), hypo-SI on T2WI. She was not able to walk and sleep due to incapacitating pain. Thus, surgical removal was performed via left partial laminectomy. Postoperatively, the radiating pain was relieved completely. Histopathologic examination revealed that the tumor consisted of chondroma, which had mature hyaline cartilage with nests of benign-appearing cells and calcium deposits in lacunae.

Key Words: Chondroma $\cdot$ Lumbar spine $\cdot$ Sciatica

\section{INTRODUCTION}

Chondroma is a slowly growing benign cartilaginous neoplasm $^{15)}$. The most common sites are long bones of the hands and feet, but sometimes it ocurrs in ribs and pelvis, and rarely intracranial bones ${ }^{6}$. Although it is the most common benign tumor of bone, it is quite rare in the spine, especially the lumbar spine $^{6,11)}$. Chondroma in the spine comprises $3 \%$ of all chondromas and is commonly encountered in the thoracic spine ${ }^{10)}$. Until now, only 15 cases of chondormas located in the lumbar spine have been reported. Although chondroma is generally asymptomatic, it may cause slowly developing neurologic deficit due to the mass effect of the lesion on the spinal cord or nerve roots $^{4}$. Here, we report a rare case of chondroma in the lumbar spine presenting acute sciatica in a 47-year-old woman.

\section{CASE REPORT}

A 47-year-old woman presented with lumbago and severe

- Received: October 28, 2013 • Revised: November 18, 2013

- Accepted: November 20, 2013

Corresponding Author: Inho Han, MD

Department of Neurosurgery, Pusan National University Hospital, 305

Gudeok-Ro, Seo-Gu, Busan 602-739, Korea

Tel: +82-51-240-7257, Fax: +82-51-244-0282

E-mail: farlateral@hanmail.net

"This study was supported by clinical research grant (2012), Busan National University Hospital

@This is an Open Access article distributed under the terms of the Creative Commons Attribution Non-Commercial License (http://creativecommons.org/ licenses/by-nc/3.0/) which permits unrestricted non-commercial use, distribution, and reproduction in any medium, provided the original work is properly cited. left leg pain for 1 week. The patient had no trauma history or any experience of similar pain. The pain was aggravated by walking. The patient complained of severe radiating pain on left L3 sensory dermatome area and reported aggravation of leg pain at 20 degrees of hip flexion by SLRT. However, there was no motor weakness on neurological examination.

Plain films of the lumbar spine showed only loss of lordotic curvature. Computed tomography (CT) revealed no bony abnormality, such as osteolysis. Magnetic resonance imaging (MRI) demonstrated a plaque-appearing extradural mass which was located in the left and posterior spinal canal at L2-3 level. The lesion was homogeneous iso-SI on T1-WI, hypo-SI on T2-WI, and peripheral rim enhancement on a gadolinium enhanced MRI (Fig. 1).

She was not able to walk and sleep due to incapacitating pain. The pain was not relieved by intravenous analgesics. We decided to perform surgical treatment. Under microscopy, left partial laminectomy was done at L2-3 level. The yellowreddish colored, and flat typed-mass was located between the dura mater and the anterior wall of the L3 lamina (Fig. 2). The mass was soft and easily separated from the dura, lamina, and pedicle. The mass was totally removed.

Histopathologic examination revealed that the tumor consisted of chondroma, which had mature hyaline cartilage with nests of benign-appearing cells and calcium deposits in lacunae (Fig. 3).

Postoperatively, the radiating pain was completely relieved. At 3 months after surgery, follow-up MRI showed no remnant mass or recurrence. The patient presented no radiating or back pain anymore. 


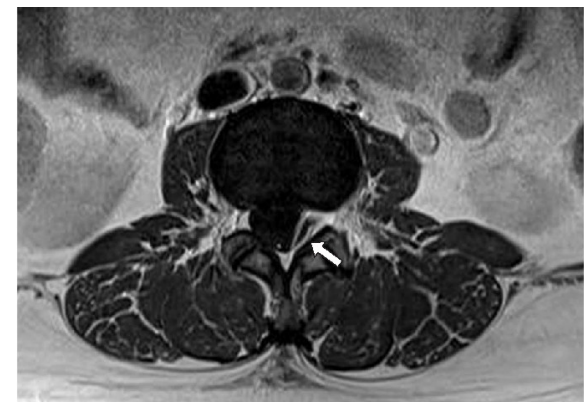

Fig. 1. Gadolinium-enhanced magnetic resonance images show a peripheral rim enhancement (white arrow).

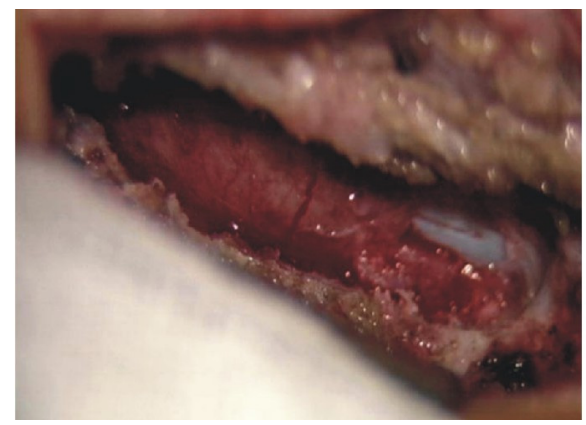

Fig. 2. The Intraoperative findings of lumbar spine chondroma. The yellow-reddish colored mass was seen in the posterior spinal canal.

\section{DISCUSSION}

Benign cartilaginous tumors are classified into four histological types: chondroma, osteochondroma, chondroblastoma, and chondromyxoid fibroma ${ }^{2,6,7,9)}$. Chondroma is the most common cartilaginous tumor, and is equivalent to $5 \%$ of all bone tumors ${ }^{6}$. The most common originated sites are long bones of the hands and feet. However, chondromas were sometimes found in the ribs, pelvis, and rarely intracranial bones $^{1,6)}$. Chondromas in the spine are very unusual pathologic entity, accounting for approximately $3 \%$ of all chondromas $^{6}$. Especially, symptomatic chondoromas of the lumbar spine are quite rare and only 16 cases including this case have been reported (Table 1) $)^{4,7,12,14)}$.

Chondromas can be subdivided into 2 types according to their site of origin: the medullary cavity (enchondroma) and the surface of periosteum (periosteal chondroma). In this case, the type of the chondroma was periosteal chondromas. The periosteal chondromas can increase in size with broad base, but usually does not infiltrate the adjacent soft tissue. Chondroma can occur at any part of the vertebra including body, pedicle, lamina and spinous process. In our review of literatures, neural arch was the most common affected location

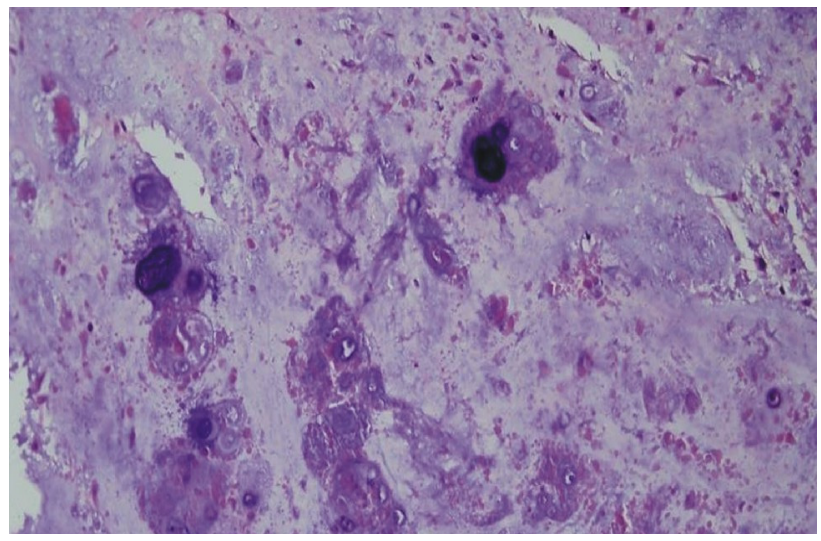

Fig. 3. Histopathologic examination showed mature hyaline cartilage with nests of benign-appearing cells and calcium deposits in lacunae (hematoxylin-eosin stain, original magnification $\times 200$ ).

in the lumbar spine, accounting on 11 out of 16 cases. Lumbar chondroma could remain asymptomatic or present with back pain, swelling, and sciatica. Although tumors arising from the pedicle or posterior spinal canal could present acute nerve compression, in most of lumbar chondroma, the symptoms slowly develop over several months. However, in current case, the patient presented with acute sciatica aggravated during 1 week without trauma or a past clinical history.

Plain films of lumbar spine show indirect signs of these lesions with smooth erosions of the bone structure, which are radiolucent area or calcification ${ }^{6,7}$. Computed tomography (CT) demonstrates a soft tissue mass with stippled calcifications and local bone destruction showing isodense or hyperdense ${ }^{3,16}$. MRI shows a subperiosteal lobulated mass at the bone surface with peripheral rim enhancement on T1WI. Also, MRI revealed hypo- to iso-SI on T1-WI, low-SI on T2WI ${ }^{4,15,17}$. Furthermore, MRI is important for differential diagnosis because tumor size, pattern, location, and relation of surrounding structures, especially cord compression can be identified ${ }^{6,14)}$.

Nevertheless, differential diagnosis of chondromas from cartilaginous tumors is often difficult based on the radiologic finding alone. Therefore, biopsy is needed for exact diagnosis $^{6}$. Gross findings of chondroma appear as lobulated and cartilaginous mass with a covering of fibrous tissue from the periosteum $^{8}$. Histopathologic findings of chondroma are composed of chondrocytes arranged in a pseudolobular fashion and may be associated with ossified regions ${ }^{3)}$.

Surgically total removal is the treatment of choice for lumbar spine chondroma. Recurrence of chondroma is rare and usually related with incomplete removal ${ }^{3,6,7}$. The important point is that approximately $10 \%$ of solitary chondromas undergo malignant progression requiring radiation therapy ${ }^{4,5,11}$. Malignant progression is related with a component of syndrome, Ollier's syndrome and Maffucci's syndrome ${ }^{4)}$. 
Table 1. Chondromas of the Lumbar spine

\begin{tabular}{|c|c|c|c|c|c|c|}
\hline Author \& Year & Age (years) & Sex & Site & $S x^{\dagger}$ duration & Clinical presentation & Origin \\
\hline Pittoni et al., $1928^{*}$ & 25 & $M$ & L1 & 8 months & Swelling & Not reported \\
\hline Peycelon et al., $1936^{*}$ & 12 & $M$ & L1 & 6 months & Swelling & Spinous processes \\
\hline Godlewski et al., $1960^{*}$ & 56 & $\mathrm{~F}$ & L1 & 8 months & Cord compression & Body \\
\hline \multirow[t]{2}{*}{ Paillas et al., $1963^{*}$} & 40 & $M$ & L5 & Not reported & Swelling & Neural arch \\
\hline & 12 & $M$ & L1 & 24 months & Pain & Neural arch \\
\hline De Mourgues et al., $1964^{*}$ & 34 & $M$ & L2 & Not reported & Swelling & Neural arch \\
\hline Nag et al., 1966 ${ }^{13)}$ & 50 & $M$ & L4 & 30 months & Sciatica & Body \\
\hline Herndon et al., 19708) & 10 & $\mathrm{~F}$ & L4 & 24 months & Sciatica & Body \\
\hline Bell et al., 1971²) & 25 & $M$ & $L 1-L 2$ & 5 days & Pain, swelling & Neural arch \\
\hline Bland et al., 19903) & 36 & $M$ & L3-L4 & 5 months & Sciatica & Neural arch \\
\hline Gaetani et al., 19967) & 44 & $M$ & L4 & 18 months & Sciatica & Neural arch \\
\hline Erten et al., 19996) & 35 & $M$ & L5-S1 & 2 year & Sciatica & Neural arch \\
\hline Motooka et al., 2002 & 66 & $M$ & $\mathrm{~L} 5$ & Not reported & Sciatica & Neural arch \\
\hline Ogata et al., 2007 ${ }^{14)}$ & 77 & $M$ & L3 & 1 month & Cord compression & Neural arch \\
\hline Cetinkal et al., 2008 & 54 & $\mathrm{~F}$ & $\mathrm{~L} 2$ & 3 year & Cord compression & Neural arch \\
\hline Present case & 47 & $\mathrm{~F}$ & L2 & 1 week & Cord compression & Neural arch \\
\hline
\end{tabular}

${ }^{*}$ Cited by Bell ${ }^{2)},{ }^{+}$Sx $=$Symptom

\section{CONCLUSION}

We report a rare case of chondroma in the lumbar spine presenting acute sciatica in a 47-year-old woman. Although lumbar chondroma is unusual and slowly growing, it should be considered in the differential diagnosis of extradural mass in patients with acute sciatica. In lumbar spine chondroma, total surgical resection is the treatment of choice for immediate relief of sciatica and avoiding a recurrence.

\section{REFERENCES}

1. Akansu B, Atik E, Altintas S, Kalaci A, Canda S: Periosteal chondroma of the ischium; an unusual location. Turk Patoloji Derg 28:172-174, 2012

2. Bell MS: Benign cartilaginous tumours of the spine. A report of one case together with a review of the literature. Br J Surg 58:707-711, 1971

3. Bland LI, McDonald JV: Chondroma of the lumbar spine, a rare cause of sciatica: Case report. Neurosurgery 26:685-687; discussion 688, 1990

4. Cetinkal A, Guven G, Topuz AK, Colak A, Demircan MN, Haholu A: Lumbar spinal chondroma presenting with radiculopathy: Case report. Turk Neurosurg 18:397-399, 2008

5. Choi H, Ahn J, Choi S, Ji C: Thoracic myelopathy caused by a chondrosarcoma involving the thoracic spine in an osteochodromatosis Patient. Kor J Spine 3:91-94, 2006

6. Erten SF, Kocak A, Mizrak B, Kutlu R, Colak A: An end-plate chondroma mimicking calcified lumbar disc herniation. A case report and review of the literature. Neurosurg Rev 22:145-148, 1999

7. Gaetani P, Tancioni F, Merlo P, Villani L, Spanu G, Baena RR: Spinal chondroma of the lumbar tract: Case report. Surg Neurol 46:534-539, 1996

8. Herndon JH, Cohen J: Chondroma of a lumbar vertebral body in a child. An unusual tumor resembling a chordoma. J Bone Joint Surg Am 52:1241-1247, 1970

9. Lichtenstein L, Hall JE: Periosteal chondroma; a distinctive benign cartilage tumor. J Bone Joint Surg Am 24A-3:691-697, 1952

10. Lozes G, Fawaz A, Perper H, Devos P, Benoit P, Krivosic I, et al: Chondroma of the cervical spine. Case report. J Neurosurg 66:128-130, 1987

11. Morard M, De Tribolet N, Janzer RC: Chondromas of the spine: Report of two cases and review of the literature. $\mathrm{Br} \mathrm{J}$ Neurosurg 7:551-556, 1993

12. Motooka Y, Kondoh T, Kurihara E, Tamaki N: [Chondroma of the lumbar spinal canal: A case report]. No To Shinkei 54: 347-351, 2002

13. Nag T, Falconer M: Enchondroma of the vertebral body. Report of a case causing bilateral sciatica. Br J Surg 53:1067-1071, 1966

14. Ogata T, Miyazaki T, Morino T, Nose M, Yamamoto H: A periosteal chondroma in the lumbar spinal canal. Case report. J Neurosurg Spine 7:454-458, 2007

15. Singh AP, Mahajan S: Periosteal chondroma of the sacrum. Can J Surg 51:E105-106, 2008

16. Willis BK, Heilbrun MP: Enchondroma of the cervical spine. Neurosurgery 19:437-440, 1986

17. Woertler K, Blasius S, Brinkschmidt C, Hillmann A, Link TM, Heindel W: Periosteal chondroma: MR characteristics. J Comput Assist Tomogr 25:425-430, 2001 